\title{
Adsorption of Ionic Liquids from Cellulosic Hydrolysate by Ion-exchange Resin
}

\author{
Haoran $\mathrm{Wu}$ \\ Sichuan University \\ College of Chemical Engineering \\ Chengdu City, China \\ e-mail: haoranwuscu@163.com
}

\author{
Shun Yao \\ Sichuan University \\ College of Chemical Engineering \\ Chengdu City, China \\ e-mail: youngsun9802@163.com
}

\author{
Yan Wang \\ Sichuan University \\ College of Chemical Engineering \\ Chengdu City, China \\ e-mail: yanwang0129@126.com \\ Hang Song* \\ Sichuan University \\ College of Chemical Engineering \\ Chengdu City, China \\ e-mail: hangsong@,vip.sina.com
}

\begin{abstract}
Ionic liquids (ILs) have got wide applications as solvent or catalyst for the conversion of saccharides into valuable chemicals due to their fascinating properties. However, some ILs inevitably occur in separation difficulty from products in aqueous samples since they do have notable solubility in water. Meanwhile, it will bring about effluent discharges. Recently, the hydrolysis of cellulose in ionic liquids has been intensively investigated, but little is known about the ionic liquids removal from the hydrolysate. This study proposes adsorption by ion-exchange resin for the removal of ILs, involved in cellulosic hydrolysate. The ionexchange resin of $\mathbf{7 3 2 H}$ with sulfonic acid functional group was applied to examine the sorption abilities for 1-butyl-3methylimidazolium chloride $([\mathrm{Bmim}] \mathrm{Cl}), 1$-propyl sulfonic acid-3-methylimidazolium

$\left(\left[\mathrm{C}_{3} \mathrm{SO}_{3} \mathrm{Hmim}\right] \mathrm{HSO}_{4}\right)$ and hydrogensulfate methanesulfonate $\left([\mathrm{HBth}] \mathrm{CH}_{3} \mathrm{SO}_{3}\right)$. The results showed that the resin of $732 \mathrm{H}$ exhibits promising sorption abilities for $[\mathrm{Bmim}] \mathrm{Cl}$ and $[\mathrm{HBth}] \mathrm{CH}_{3} \mathrm{SO}_{3}$, while no sorption on $\left[\mathrm{C}_{3} \mathrm{SO}_{3} \mathrm{Hmim}\right] \mathrm{HSO}_{4}$. The static desorption experiment of ionic liquids was investigated, the results indicated that $\mathbf{9 2 . 0 5 \%}$ of [Bmim]Cl can be eluted from the [Bmim]Clloaded resin. Under the same elution conditions, $90.04 \%$ of [Bmim]Cl and $52.95 \%$ of $[\mathrm{HBth}] \mathrm{CH}_{3} \mathrm{SO}_{3}$ can be eluted from the $[\mathrm{Bmim}] \mathrm{Cl} \cdot[\mathrm{HBth}] \mathrm{CH}_{3} \mathrm{SO}_{3}$-loaded resin. This study is expected to be helpful in the ILs recycling and the treatment of water pollution.
\end{abstract}

Keywords- Adsorption; ion-exchange resin; ionic liquid; cellulosic hydrolysate; desorption

\section{INTRODUCTION}

Ionic liquids (ILs) have developed wide applications as solvent or catalyst in a range of fields due to their negligible vapor pressure, non-flammability, high thermal stability and tunable solubility. Moreover, the specific properties of ILs can be designed by appropriate modification of the cations or anions [1]. This flexibility has earned them wide applications. Until now, many studies have demonstrated that ILs can be successfully used not only in industrial applications, including Diels-
Alder[2-6], Heck[7-11] and Friedel-Crafts[12-16] reactions, but also in academic applications, such as cellulose derivatization [17-19] and hydrolysis [20,21].

The property of negligible vapor pressure means that ILs do not evaporate and induce air pollution. However, most ILs are water soluble and have poor biodegradability $[22,23]$. So, the ILs are not always green. If released into the aquatic environment, they could cause severe water pollution due to their high water miscibility, potential toxicity and poor biodegradability. Although these problems cannot be overlooked, the removal of ILs from industrial effluent or reaction system has not received much research attention.

Palomar and coworkers [24] and Farooq et al. [25] determined the adsorption behavior of imidazolium- or pyridinium-based ILs onto the activated carbon. Although Choi [26] proposed adsorption by ion-exchange resins for the removal of 1-ethyl-3-methylimidazolium acetate ([EMIM]OAc), the [EMIM]OAc was chosen as a model IL dissolved in water in this work. Nevertheless, the actual reaction system, especially cellulosic hydrolysate, little is known about the ionic liquids removal from the hydrolysate. In this study, two kinds of cellulosic hydrolysate were selected to demonstrate the removal activities of ILs from aqueous media and products.

\section{EXPERIMENTAL}

\section{A. Materials}

The structures of ionic liquids ([Bmim $] \mathrm{Cl}$, $\left[\mathrm{C}_{3} \mathrm{SO}_{3} \mathrm{Hmim}\right] \mathrm{HSO}_{4}$ and $\left.[\mathrm{HBth}] \mathrm{CH}_{3} \mathrm{SO}_{3}\right)$ used for this study are displayed in Fig .1 and their purities are all above $97 \%$. The resin of $732 \mathrm{H}$ was supplied by Kelong Chemical Co., Ltd. (Chengdu, China). All other reagents were analytical grade or higher in purity, purchased from commercial sources in China. 


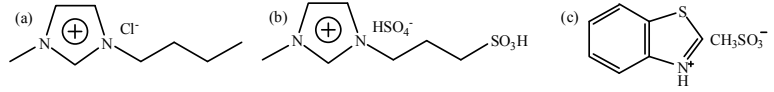

Figure 1. Ionic liquids used in this study: (a) $[\mathrm{Bmim}] \mathrm{Cl}$, (b) $\left[\mathrm{C}_{3} \mathrm{SO}_{3} \mathrm{Hmim}\right] \mathrm{HSO}_{4}$, (c) [HBth] $\mathrm{CH}_{3} \mathrm{SO}_{3}$

\section{B. Preparation of cellulosic hydrolysate}

Solution with $2.5 \mathrm{wt} \%$ bagasse cellulose in $[\mathrm{Bmim}] \mathrm{Cl}$ was prepared under vigorous stirring at $100 \mathrm{oC}$ to form a transparent solution, followed by the addition of a small amount of water and acidic IL ([HBth $] \mathrm{CH}_{3} \mathrm{SO}_{3}$ or $\left[\mathrm{C}_{3} \mathrm{SO}_{3} \mathrm{Hmim}\right] \mathrm{HSO}_{4}$, as catalyst). The mixture was stirred at a reaction temperature for a certain time. After reaction, the sample was quenched immediately by adding some of ultrapure water. The supernatant was subjected to dilute for adsorption experiment.

\section{Adsorption and desorption experiment}

The resin of $732 \mathrm{H}(1 \mathrm{~g})$ was brought into $25 \mathrm{~mL}$ of cellulosic hydrolyate in a $100 \mathrm{~mL}$ Erlenmeyer flask. The flasks were then kept in a shaker at $30{ }^{\circ} \mathrm{C}$ for a specified time. After adsorption during the predetermined time, the resin was separated and the remaining concentrations of ILs were determined using UV-vis spectrophotometer, after appropriate dilution. The adsorption efficiency was calculated using the following equation:

$$
\mathrm{E}(\%)=\left(\mathrm{C}_{0}-\mathrm{C}_{1}\right) / \mathrm{C}_{0} \times 100 \%
$$

Where $\mathrm{E}(\%)$ represents the adsorption efficiency percentage, $\mathrm{C}_{0}$ and $\mathrm{C}_{1}$ are the concentrations $(\mu \mathrm{g} / \mathrm{mL})$ of ILs before and after adsorption, respectively.

In the static desorption experiments, the IL-loaded resin was mixed with $25 \mathrm{~mL} \mathrm{HCl}$ solution in a $100 \mathrm{~mL}$ Erlenmeyer flask under agitation at $150 \mathrm{rpm}$. The released concentration of IL was evaluated by UV-vis spectrophotometer. The desorption efficiency can be described by

$$
\mathrm{D}(\%)=\mathrm{C}_{2} /\left(\mathrm{C}_{0}-\mathrm{C}_{1}\right) \times 100 \%
$$

Where $\mathrm{D}(\%)$ represents the desorption efficiency percentage, $\mathrm{C}_{2}$ is the concentration of ILs in desorption solution $(\mu \mathrm{g} / \mathrm{mL}), C_{0}$ and $C_{1}$ are the same as described above.

\section{Determination of standard curve of IL and TRS}

Standard curve of ILs and TRS was established by TU1810 UV-spectrophotometer at maximum absorption wavelength of $210 \mathrm{~nm}$ for 1-butyl-3-methylimidazolium chloride $([\mathrm{Bmim}] \mathrm{Cl}), 211 \mathrm{~nm}$ for 1-propyl sulfonic acid-3methylimidazolium hydrogensulfate $\left(\left[\mathrm{C}_{3} \mathrm{SO}_{3} \mathrm{Hmim}\right] \mathrm{HSO}_{4}\right)$, $252 \mathrm{~nm}$ for benzothiazolium methanesulfonate ([HBth] $\mathrm{CH}_{3} \mathrm{SO}_{3}$ ) and 490nm for total redusing sugars (TRS) with redistilled water as reference. The TRS was measured using phenol-sulfuric acid method. And the concentration of TRS was calculated based on the standard curve obtained with glucose.

ILs/TRS-water solutions of different concentration were prepared and their absorbance was measured at maximum absorption wavelength, regression equation with favourable linear correlation between absorbance with concentration was arrived as $\mathrm{y}=0.0237 \mathrm{x}+0.0254$,
$\mathrm{R}^{2}=0.9983([\mathrm{Bmim}] \mathrm{Cl}) ; \quad \mathrm{y}=0.0247 \mathrm{x}+0.0109, \quad \mathrm{R}^{2}=0.9996$ $\left([\mathrm{HBth}] \mathrm{CH}_{3} \mathrm{SO}_{3}\right) ; \quad \mathrm{y}=0.0146 \mathrm{x}+0.0156, \quad \mathrm{R}^{2}=0.9923$ $\left(\left[\mathrm{C}_{3} \mathrm{SO}_{3} \mathrm{Hmim} \mathrm{HSO}_{4}\right) ; \quad \mathrm{y}=0.0182 \mathrm{x}+0.0241, \quad \mathrm{R}^{2}=0.9973\right.$ (TRS). The standard curve was showed in Fig.2.

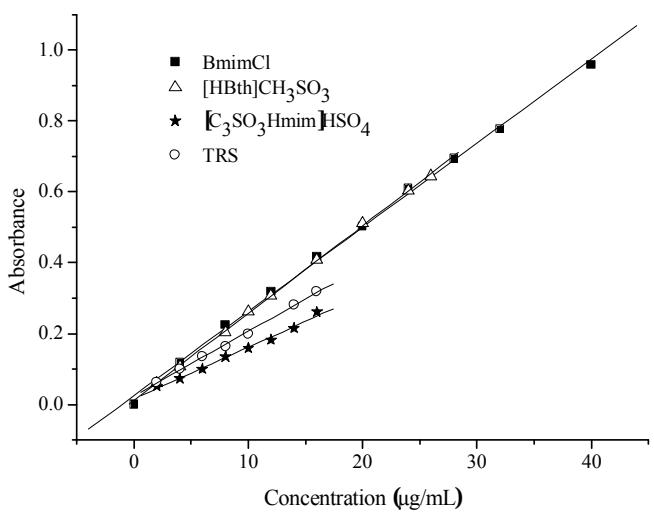

Figure 2. Standard curve of ILs and TRS

\section{RESULTS AND DISCUSSION}

A. The comparison of adsorption capacity in two kinds of cellulosic hydrolysate.

Two kinds of cellulosic hydrolysate were employed to determine the adsorption abilities for ILs. The results of the adsorption performance of $732 \mathrm{H}$ resin on ILs and the main product (TRS) are given in Fig .3. It is interesting to note that the resin exhibits a promising adsorption capacity on $[\mathrm{Bmim}] \mathrm{Cl}$. However, with regard to the catalyst IL ([HBth $] \mathrm{CH}_{3} \mathrm{SO}_{3}$ or $\left[\mathrm{C}_{3} \mathrm{SO}_{3} \mathrm{Hmim}\right] \mathrm{HSO}_{4}$ ), the resin showed a remarkably well adsorption ability on $[\mathrm{HBth}] \mathrm{CH}_{3} \mathrm{SO}_{3}$ than $\left[\mathrm{C}_{3} \mathrm{SO}_{3} \mathrm{Hmim}\right] \mathrm{HSO}_{4}$. Resultantly, the adsorption efficiency for [HBth] $\mathrm{CH}_{3} \mathrm{SO}_{3}$ reached $100 \%$, while it was only $1 \%$ for $\left[\mathrm{C}_{3} \mathrm{SO}_{3} \mathrm{Hmim}\right] \mathrm{HSO}_{4}$. This result can be due to the stronger $\pi-\pi$ interaction between aromatic nucleus of resin with benzothiazolium ring than with imidazolium ring. Another primary reason is that $\left[\mathrm{C}_{3} \mathrm{SO}_{3} \mathrm{Hmim}\right] \mathrm{HSO}_{4}$ possesses a sulfonic acid functional group in its cation.
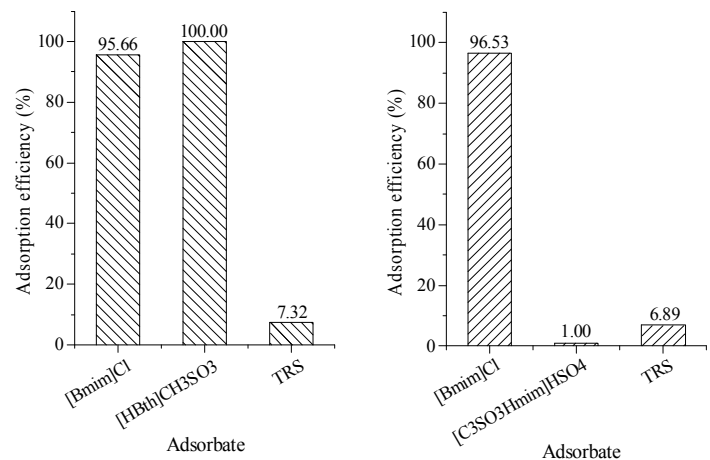

Figure 3. The comparison of adsorption capacity in two kinds of cellulosic hydrolysate

\section{B. Effect of adsorption time}

As seen from Fig .4, the adsorption rate was very fast and the adsorption efficiency increased rapidly with increasing time. Results showed that the adsorption 
efficiency reached a plateau beyond $80 \mathrm{~min}$, indicating that adsorption equilibrium was achieved. Because the ionexchange resin of $732 \mathrm{H}$ has almost no adsorption for $\left[\mathrm{C}_{3} \mathrm{SO}_{3} \mathrm{Hmim}\right] \mathrm{HSO}_{4}$, therefore, the figure of ion-exchange resin of $732 \mathrm{H}$ for $\left[\mathrm{C}_{3} \mathrm{SO}_{3} \mathrm{Hmim}\right] \mathrm{HSO}_{4}$ adsorption was not displayed.

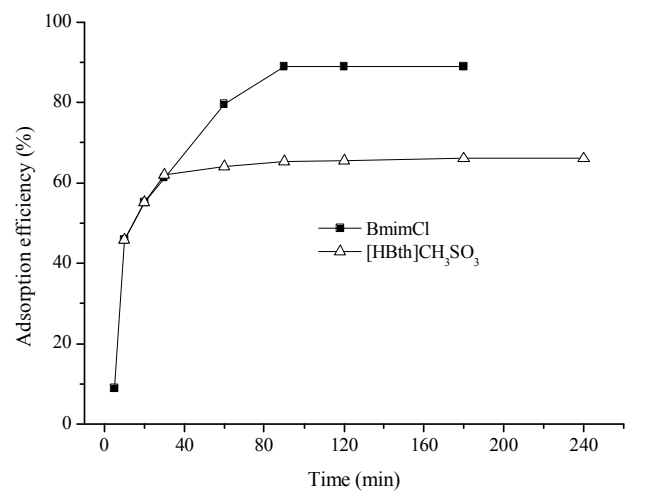

Figure 4. Effect of adsorption time

\section{Static Desorption}

In this study, the concentration of $\mathrm{HCl}$ had an important impact on the desorption process. As shown in Fig .5, the desorption efficiency increased with increasing the concentration of $\mathrm{HCl}$, thus an aqueous solution of $15 \%$ $\mathrm{HCl}$ was selected as eluting agent. As a result, $92.05 \%$ of $[\mathrm{Bmim}] \mathrm{Cl}$ can be eluted from the [Bmim]Cl-loaded resin. Under the same elution conditions, $90.04 \%$ of $[\mathrm{Bmim}] \mathrm{Cl}$ and $52.95 \%$ of $[\mathrm{HBth}] \mathrm{CH}_{3} \mathrm{SO}_{3}$ can be eluted from the $[\mathrm{Bmim}] \mathrm{Cl} \cdot[\mathrm{HBth}] \mathrm{CH}_{3} \mathrm{SO}_{3}$-loaded resin. The relative low desorption efficiency of [HBth] $\mathrm{CH}_{3} \mathrm{SO}_{3}$ may be attributed as the strong $\pi-\pi$ interaction between aromatic nucleus of resin with benzothiazolium ring.

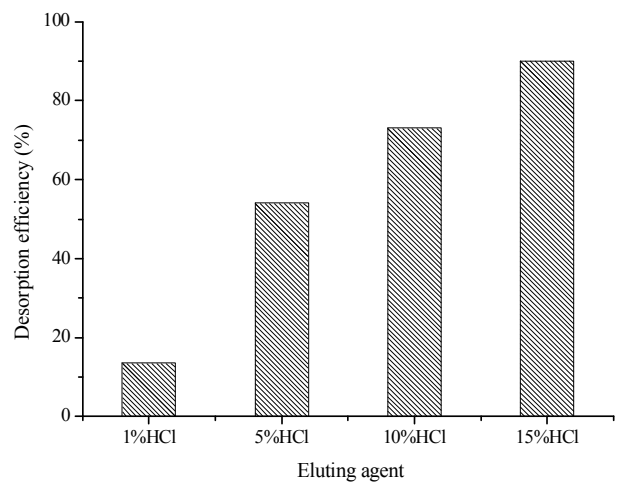

Figure 5. The effect of concentration of $\mathrm{HCl}$ on desorption efficiency

\section{CONCLUSIONS}

Ion-exchange resin was evaluated to determine the adsorption performance for ILs in cellulosic hydrolysates. As a result, the resin of $732 \mathrm{H}$ exhibits promising sorption abilities for $[\mathrm{Bmim}] \mathrm{Cl}$ and $[\mathrm{HBth}] \mathrm{CH}_{3} \mathrm{SO}_{3}$, especially for [HBth $] \mathrm{CH}_{3} \mathrm{SO}_{3}$, while no sorption for $\left[\mathrm{C}_{3} \mathrm{SO}_{3} \mathrm{Hmim}\right] \mathrm{HSO}_{4}$. The result can be due to the stronger $\pi-\pi$ interaction between aromatic nucleus of resin with benzothiazolium ring than with imidazolium ring. Another primary reason is that $\left[\mathrm{C}_{3} \mathrm{SO}_{3} \mathrm{Hmim} \mathrm{HSO}_{4}\right.$ possesses a sulfonic acid functional group in its cation. The static desorption experiment of ionic liquids was investigated, the result indicated that $92.05 \%$ of $[\mathrm{Bmim}] \mathrm{Cl}$ can be eluted from the [Bmim $] \mathrm{Cl}$-loaded resin. Under the same elution conditions, $90.04 \%$ of $[\mathrm{Bmim}] \mathrm{Cl}$ and $52.95 \%$ of $[\mathrm{HBth}] \mathrm{CH}_{3} \mathrm{SO}_{3}$ can be eluted from the $[\mathrm{Bmim}] \mathrm{Cl} \cdot[\mathrm{HBth}] \mathrm{CH}_{3} \mathrm{SO}_{3}$-loaded resin. This work is expected to be helpful in the ILs recycling and the treatment of water pollution.

\section{ACKNOWLEDGMENT}

This work was financially supported by the National Scientific Foundation of China (81102344) and 2013 scientific research foundation of Sichuan University for Outstanding Young Scholars.

\section{REFERENCES}

[1] M.J. Earle and K.R. Seddon, "Ionic liquids. Green solvents for the future," Pure and Applied Chemistry, vol. 72, 2000, pp. 1391-1398, doi:.

[2] C. Chiappe, M. Malvaldi, and C. S. Pomelli, "The solvent effect on the Diels-Alder reaction in ionic liquids: multiparameter linear solvation energy relationships and theoretical analysis," Green Chem, vol. 12, 2010, pp. 1330-1339, doi: 10.1039/c0gc0074d.

[3] X. Zheng, Y. Qian, and Y. Wang, "Direct asymmetric aza DielsAlder reaction catalyzed by chiral 2-pyrrolidinecarboxylic acid ionic liquid," Catalysis Communications, vol. 11, 2010, pp. 567570, doi: 10.1016/j.catcom.2009.12.021

[4] O. Bortolini, A. D. Nino, A. Garofalo, L. Maiuolo, A. Procopio, and B. Russo, "Erbium triflate in ionic liquids: A recyclable system of improving selectivity in Diels-Alder reactions," Applied Catalysis A: General, vol. 372, 2010, pp. 124-129, doi:10.1016/j.apcata.2009.10.020

[5] A. D. Nino, O. Bortolini, L. Maiuolo, A. Garofalo, B. Russo, and G. Sindona, "A sustainable procedure for highly enantioselective organocatalyzed Diels-Alder cycloadditions in homogeneous ionic liquid/waster phase," Tetrahedron Letters, vol. 52, 2011, pp. 1415 1417, doi: 10.1016/j.tetlet.2011.01.014

[6] N. D. Khupse and A. Kumar, "The cosolvent-Directed Diels-Alder reaction in ionic liquids," J. Phys. Chem. A, vol. 115, 2011, pp. 10211-10217, doi: org/10.1021/jp.205181e

[7] Y. Zeng, Y. Wang, Y. Xu, Y. Song, J. Jiang, and Z. JIN, "Pd Nanoparticles in the thermoregulated ionic liquid and organic biphasic system: An efficient and recyclable catalyst for Heck reaction," Catal. Lett, vol. 143, 2013, pp. 200-205, doi: 10.1007/s10562-012-0919-9

[8] D. S. Gaikwad, Y. Park, and D. M. Pore, "A novel hydrophobic fluorous ionic liquid for ligand-free Mizoroki-Heck reaction," Tetrahedron Letters, vol. 53, 2012, pp. 3077-3081, doi: org/10.1016/j.tetlet.2012.04.027

[9] P. Nehra, B. Khungar, K. Pericheria, S.C. Sivascubramanian, and A. Kumar, "Imidazolium ionic liquid-tagged palladium complex: an efficient catalyst for the Heck and Suzuki reactions in aqueous media," Green. Chem, 2014, doi: 10.1039/c4gc00525b

[10] X. Shi, X. Han, W. Ma, J. Fan, and J. Wei, "A $\mathrm{PdCl}_{2}$-ionic liquid brush assembly: an efficient and reusable catalyst for MizorokiHeck reaction in neat water," Appl. Organometal. Chem, vol. 26, 2012, pp. 16-20, doi: 10.1002/aoc.1857

[11] R. Kumar, A. Shard, R. Bharti, Y. Thopate, and A. K. Sinha, "Palladium-Catalyzed Dehydrative heck olefination of secondary aryl alcohols in ionic liquids: towards a waste-free strategy for tandem synthesis of stilbenoids," Angew. Chem. Int. Ed, vol. 51, 2012, pp. 2632-2639, doi: 10.1002/anie.201107261

[12] P. H. Tran, F. Duus, T. N. Le, "Friedel-Crafts acylation using bismuth triflate in $[\mathrm{BMI}]\left[\mathrm{PF}_{6}\right]$," Tetrahedron Letters, vol. 53, 2012, pp. 222-224, doi: 10.1016/j.tetlet.2011.11.022 
[13] P. H. Tran, N. B. Do, and T. Ngocle, "Improvement of the FriedelCrafts benzoylation by using bismuth trifluoromethanesulfonate in 1-butyl-3-methylimidazolium trifluoromethanesulfonate ionic liquid under microwave irradiation," Tetrahedron Letters, vol. 55, 2014, pp. 205-208, doi: org/10.1016/j.tetlet.2013.10.155

[14] Y. Luo, A. Pan, M. Xing, M. Chen, and J. Xie, "Synthesis of 1acetylpyrene via Friedel-Crafts Reaction Using Chloroaluminate Ionic Liquids as Dual Catalyst and Solvent," Advanced Materials Research, vol. 443-444, 2012, pp. 917-922, doi: 10.4028/www.scientific.net/AMR.443-444.917

[15] S. Kazemi, C.J. PETERS, and M. C. Kroon, "Phase Behavior of the Ternary System Acetylferrocene, The Ionic Liquid 1-Butyl-3methylimidazolium Bis(trifluoromethylsulfonyl)imide, and Carbon Dioxide To Be Applied in Friedel-Crafts Acylation Reactions," J. Chem. Eng. Data, vol. 58, 2013, pp. 951-955, doi: org/10.1021/je301241kl

[16] L. Z. Fekri and M. Nikpassand, "Ultrasound-Promoted FriedelCrafts Acylation of Arenes and Cyclic Anhydrides Catalyzed by Ionic Liquid of $[\mathrm{bmim}] \mathrm{Br} / \mathrm{AlCl}_{3}$," Russian Journal of General Chemistry, vol. 84, 2014, pp. 1825-1829, doi: 10.1134/S107036321409031X

[17] M. Gericke, P. Fardim, and T. Heinze, "Ionic Liquids-Promising but Challenging Solvents for Homogeneous Derivatization of Cellulose," molecules, vol. 17, 2012, pp. 7458-7502, doi: 10.3390/molecules 17067458

[18] F. Hong, X. Guo, S. Zhang, S. Han, G. Yang, and L. Jönsson, "Bacterial cellulose production from cotton-based waste textiles: Enzymatic saccharification enhanced by ionic liquid pretreatment," Bioresource Technology, vol. 104, 2012, pp. 503-508, doi: 10.1016/j.biortech.2011.11.028
[19] Y. Yang, H. Xie, and E. Liu, "Acylation of cellulose in reversible ionic liquids," Green Chem, vol. 16, 2014, pp. 3018-3023, doi: 10.1039/c4gc00199k

[20] K. Shill, S. Padmanabhan, Q. Xin, J. M. Prausnitz, D. S. Clark, and H. W. Blanch, "Ionic Liquid Pretreatment of Cellulosic Biomass: Enzymatic Hydrolysis and Ionic Liquid Recycle," Biotechnology and Bioengineering, vol. 108, 2011, pp. 511-520, doi: $10.1002 /$ bit. 23014

[21] H. Guo, X. Qi, L. Li, and R. L. Smithjr, "Hydrolysis of cellulose over functionalized glucose-derived carbon catalyst in ionic liquid," Bioresource Technology, vol. 116, 2012, pp. 355-359, doi: org/10.1016/j.biortech.2012.03.098

[22] M. T. Garcia, N. Gathergood, and P. J. Scammells, "Biodegradable ionic liquids Part II. Effect of the anion and toxicology," Green. Chem, vol. 7, 2005, pp. 9-14, doi: 10.1039/b411922c

[23] N. Gathergood and P. J. Scammells, "Design and Preparation of Room-Temperature ionic liquids containing biodegradable side chains," Aust. J. Chem, vol. 55, 2002, pp. 557-560, doi: $10.1071 / \mathrm{CH} 02148$

[24] J. Palomar, J. Lemus, M. A. Gilarranz, and J.J.Rodriguez, "Adsorption of ionic liquids from aqueous effluents by activated carbon," Carbon, vol.47, 2009, pp. 1846-1856, doi: 10.1016/j.carbon.2009.03.028

[25] A. Farooq, L. Reinert, J. Levêquea, N. Papaiconomou, N. Irfan, and L. Duclaux, "Adsorption of ionic liquids onto activated carbons: Effect of $\mathrm{pH}$ and temperature," Microporous and Mesoporous Materials, vol. 158, 2012, pp. 55-63, doi: 10.1016/j.micromeso.2012.03.008

[26] S. B. Choi, S. W. Won, and Y. S. Yun, "Use of ion-exchange resins for the adsorption of the cationic part of ionic liquid, 1-ethyl3-methylimidazolium," Chemical Engineering Journal, vol. 214 2013, pp. 78-82, doi: 10.1016/j.cej.2012.10.035 